Acta Horticulturae et Regiotecturae - Special Issue

Nitra, Slovaca Universitas Agriculturae Nitriae, 2021, pp. 27-30

\title{
CLIMATE CHANGE IMPACT ON THE GLACIERS OF THE RIONI RIVER BASIN (GEORGIA)
}

\author{
George KORDZAKHIA ${ }^{1 *}$, Larisa SHENGELIA' ${ }^{1}$, Genadi TVAURI², Murman DZADZAMIA ${ }^{3}$ \\ ${ }^{1}$ Georgian Technical University, Tbilisi, Georgia \\ ${ }^{2}$ Ivane Javakhishvili Tbilisi State University, Tbilisi, Georgia \\ ${ }^{3}$ National Environmental Agency, Tbilisi, Georgia
}

\begin{abstract}
Since the beginning of the $21^{\text {st }}$ century, studies of glaciers in Georgia have become more important, because the degradation of glaciers causes an increase in the intensity and frequency of natural disasters of a glacial and hydrological nature, an increase in water levels in the Black Sea, and a changes in river water regime. Studying the current state of the ice sheet in Georgia is an important national economic task, and to obtainobtaining a scientifically sound answer on modern conditions of the glaciers, due to the impact of current climate change is an urgent task. To solve this task, high-resolution satellite remote sensing (SRS) is used. The r. Rioni basin (West Georgia) is one of the most important glacier basins in Georgia, where the powerful glaciers are spread and their change is of great interest. In this work there are presented the results of the study of $r$. Rioni glasiers glaciers degradation due to the influence of current climate change including the expected time of their full melting.
\end{abstract}

Keywords: Georgian glaciers, degradation, climate change, satellite remote sensing

The cryosphere (including, snow, glaciers, permafrost, lake and river ice) is an integral element of high mountain regions, which are home for about $10 \%$ of the global population. Widespread cryosphere changes affect physical, biological and human systems in the mountains and surrounding lowlands, with impacts evident even in the ocean/sea (IPCC Special Report on the Ocean and Cryosphere in a Changing Climate, 2018). Observations show general decline of glaciers due to the climate change in recent decades with high confidence and likely this is most negative in the southern Andes, Caucasus and the European Alps/Pyrenees.

The World Meteorological Organization (WMO) held High Mountain Summit in Geneva (Switzerland) at the end of 2019. At the summit work, the priority importance was assigned to cryosphere problems.

Scientific studies of glaciers in the Caucasus, namely in Georgia began in the second half of the $19^{\text {th }}$ century. Several scientists of different generations participated in field works, which began in 1860 in the former Russian Empire and continued throughout the 70sn in the Soviet Union (Abikh, 1870; Khatisyan, 1864; Tsomaia and Drobishev, 1970). The outputs of these studies were summarized and presented in several issues of the glacier catalog (hereinafter - the catalog) of the former Soviet Union (Maruashvili et. al., 1975; Tsomaia, 1975; Panov, Borovik, 1977; Tsomaia, Drobishev, 1977).

The Georgian glaciers in this catalog were not presented independently and were systematized as a part of the Caucasian system of glaciers. Due to the importance of this catalog, it was later included in the World Glacier Inventory (WGI).

Under the conditions of global warming (approximately from the second half of the $20^{\text {th }}$ century), the glaciers of Georgia are have been retreating and degrading (Kordzakhia et al., 2016; Kordzakhia et al., 2019). At present, glaciers research is stipulated to indicate climate change impact on glaciers at regional and global scales, surface water level rise in oceans/ seas, landscape changes due to melting glaciers, and increasing occurrence of natural disasters related to glaciers.

The aim of this study is to determine changes of glaciers of r. Rioni basin (Western Georgia) due to the global climate change.

\section{Material and method}

The study region is the glacial basin of the $r$. Rioni basin (Western Georgia). This glacial basin is located in a high mountain region on the watershed ridge of the Central Caucasus from Mount Namkwami to Mount Kozihokh, where mountain ranges are more than 4,000 $\mathrm{m}$ high.

To give a scientifically based answer to the glaciers degradation under the impact of modern climate change and determine the corresponding risks of glacier related disasters, it is necessary to use high-resolution satellite remote sensing (SRS), since it allows studying glaciers in the large regions with the necessary resolution and accuracy within limited material and human resources and time. 
Technological and methodological approaches based on SRS were tested both by foreign researchers, for example (Pellika and Gareth Rees, 2010) and by the authors of this work (Kordzakhia et al., 2016; Kordzakhia et al., 2019), shows showing that it is possible to determine all glaciers main characteristics, i.e. maximum length, area, minimum and maximum heights, firn line-height, accumulation, and ablation areas. The basis of methodology used by authors' is application of historical data (Maruashvili et. al., 1975; Tsomaia, 1975; Panov, Borovik, 1977; Tsomaia and Drobishev, 1977), glacier schemes from the catalog, existing field works outputs along with SRS data and the use of expert knowledge. The methodology includes the implementation of necessary procedures for the quality assessment and quality control (QA/QC) of SRS data (Kordzakhia et al., 2016).

The influence of the current climate change on Georgia's glaciers is revealed in the statistics of melting of small glaciers (area in the range from 0.1 to $0.5 \mathrm{~km}^{2}$ ); it can be characterized by changes in both integral and detailed characteristics of glaciers: the area and number of glaciers in glacial basins and retreat dynamics of large glaciers (area of more than $2 \mathrm{~km}^{2}$ ). In the work, the glacial basin of the r. Rioni, which is one of the most powerful and important basins of Georgia, was analysed. For this purpose, SRS images, namely, Landsat data (resolution 15-30 m) and the data of "Global measurements of land ice from space" (GLIMS) were used. Google Earth is an effective program that offers satellite images with a high spatial resolution (0.5-0.8 m), which makes it possible to more accurately determine the contours of the glacier.

\section{Results and discussion}

To determine the impact of the climate change on the present glacial basin, the glaciers data derived from the SRS are compared with the corresponding data from the catalog. A 50-year difference between the catalog and SRS data (2015) creates the prerequisite for determining changes in basins glacialisation.

The schematic diagrams of glaciers (Figure 1a) from the catalog and GLIMS data were used to identify all glaciers from the r. Rioni basin i.e. determine the locations and quantities of glaciers in the images of SRS. In Figure 1a, as an example, the identification of the Boko glacier in the r. Rioni basin is given. The next step is to determine the area of the studied glaciers in the SRS images and compare them with the data of the same glaciers from the catalog and topographic maps of the 60 s of the last century (Figure $1 \mathrm{~b}$ ). Comparing the contours of glaciers obtained from SRS data with the contours on topographic maps, it was found that the areas of all glaciers in Georgia have declined over the past 50 years.

Data on the area of some glaciers in the catalog were less lower than those accessed from SRS and topographic maps, giving the impression that the area of such glaciers increased in comparison with the $60 \mathrm{~s}$. Using the outlines of glaciers shown on a topographic map of the same period, the inaccurate catalog were was corrected.

Table 1 shows the main characteristics of the glaciers of the Rioni river basin (№ 388-400) according to the SRS (column (1)), catalog (column (2)) and corrected inaccurate

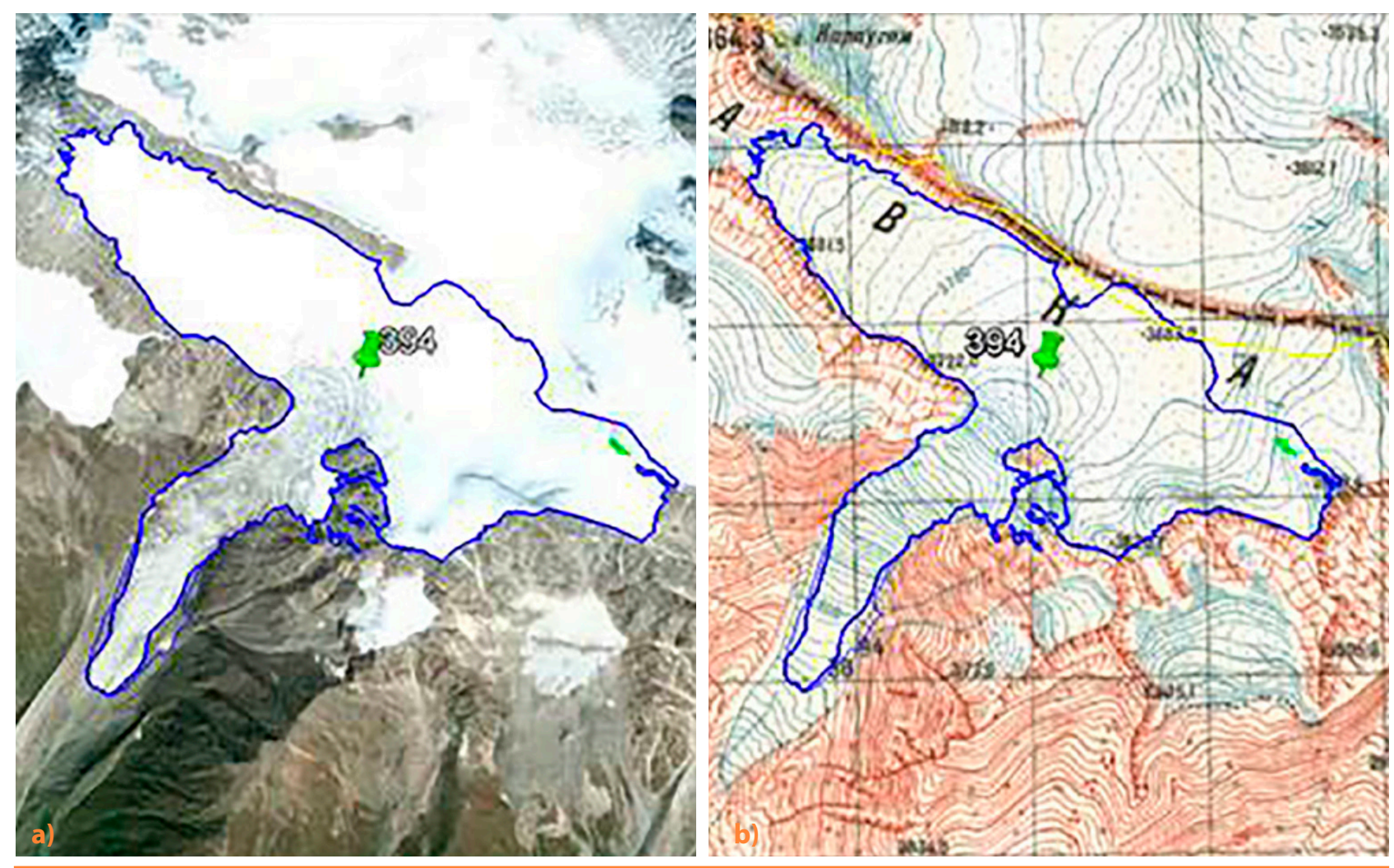

Figure 1 Boko Glacier - No. 394: a. in a) - satellite image; and b) - on a topographic map of the 60s of the last century. The contours of the glacier are shown in blue, both on a satellite image and on a topographic map 
Table 1 The main characteristics of the glaciers (№388-400) of the Rioni river basin according to SRS (1), catalog (2) and corrected inaccurate data catalog (3)

\begin{tabular}{|c|c|c|c|c|c|c|c|c|c|c|c|c|}
\hline \multirow{2}{*}{ № } & \multirow{2}{*}{$\begin{array}{l}\text { Glacier Name } \\
\text { and № from } \\
\text { WGI catalog }\end{array}$} & \multirow{2}{*}{$\begin{array}{l}\text { Identification } \\
\text { №, ID according } \\
\text { to WGI }\end{array}$} & \multirow{2}{*}{$\begin{array}{l}\text { Glacier } \\
\text { № on SRS } \\
\text { image }\end{array}$} & \multicolumn{2}{|c|}{ Max. length (km) } & \multicolumn{3}{|c|}{ Area $\left(\mathrm{km}^{2}\right)$} & \multicolumn{2}{|c|}{ Min. elevation (m) } & \multicolumn{2}{|c|}{ Max. elevation (m) } \\
\hline & & & & (1) & (2) & (1) & (2) & (3) & (1) & (2) & (1) & (2) \\
\hline 1 & 353 & SU5T09106388 & 388 & 1.5 & 1.5 & 0.6 & 0.7 & & 3,090 & 2,930 & 3,627 & 3,810 \\
\hline 2 & $* * *$ & $* * *$ & $* * *$ & & & 0.06 & & & & & & \\
\hline 3 & $\begin{array}{c}\text { Natsarula, } \\
355 a\end{array}$ & SU5T09106389 & 389 & 2.3 & 2.0 & 1.0 & 1.3 & & 3,052 & 2,700 & 3,923 & 3,750 \\
\hline 4 & $355 b$ & SU5T09106390 & 390 & 0.6 & 0.9 & 0.1 & 0.2 & & 3,494 & 3,050 & 3,875 & 3,650 \\
\hline 5 & $355 c$ & SU5T09106391 & 391 & 2.6 & 3.2 & 1.0 & 1.2 & & 3,032 & 2,550 & 4,315 & 3,820 \\
\hline 6 & 356 & SU5T09106392 & 392 & 0.8 & 0.7 & 0.3 & 0.3 & 0.3 & 3,170 & 3,130 & 3,491 & 3,520 \\
\hline 7 & Kotsan-sara & SU5T09106393 & 393 & 1.2 & 1.6 & 1.0 & 1.2 & & 3,246 & 3,060 & 3,864 & 3,750 \\
\hline 8 & Boko & SU5T09106394 & 394 & 4.2 & 4.5 & 3.7 & 4.6 & & 2,616 & 2,450 & 3,996 & 3,900 \\
\hline 9 & $* * *$ & $* * *$ & $* * *$ & & & 0.2 & & & & & & \\
\hline 10 & 361 & SU5T09106395 & 395 & 0.7 & 0.8 & 0.4 & 0.5 & & 3,202 & 3,150 & 3,532 & 3,460 \\
\hline 11 & Tbilisa,362 & SU5T09106396 & 396 & 3.3 & 3.3 & 3.6 & 3.1 & 3.8 & 2,940 & 2,750 & 4,422 & 3,920 \\
\hline 12 & Buba,363 & SU5T09106397 & 397 & 3.0 & 2.7 & 2.3 & 1.6 & 2.9 & 2,943 & 2,760 & 3,950 & 4,050 \\
\hline 13 & 364 & SU5T09106398 & 398 & 0.7 & 0.6 & 0.2 & 0.1 & 0.4 & 3,201 & 3,160 & 3,500 & 3,450 \\
\hline \multirow{2}{*}{14} & \multirow{2}{*}{$\begin{array}{c}\text { Chanc-hakhi, } \\
\text { 365a }\end{array}$} & \multirow{2}{*}{ SU5T09106399 } & $399 a$ & 2.3 & 2.9 & 0.8 & 1.4 & & 3,042 & 2,850 & 4,297 & 4,020 \\
\hline & & & $399 b$ & 0.9 & & 0.3 & & & 3,273 & & 4,115 & \\
\hline 15 & $365 b$ & SU5T09106400 & 400 & 0.3 & 0.7 & 0.1 & 0.2 & & 3,281 & 3,180 & 3,599 & 3,490 \\
\hline
\end{tabular}

Table 2

The area and number of glaciers of the r. Rioni basin

\begin{tabular}{|c|c|c|c|c|c|c|c|}
\hline \multicolumn{8}{|c|}{ Rioni river basin } \\
\hline \multicolumn{2}{|l|}{ Glaciers № } & \multicolumn{3}{|c|}{ area } & \multicolumn{3}{|c|}{ quantity } \\
\hline \multirow{5}{*}{$296,335-409$} & size & (1) & (2) & $\Delta$ & (1) & (2) & $\Delta$ \\
\hline & small & 9.2 & 11.3 & -2.1 & 36 & 47 & -11 \\
\hline & medium & 28.2 & 14.6 & 13.6 & 29 & 13 & 16 \\
\hline & large & 36 & 25.9 & 10.1 & 11 & 8 & 3 \\
\hline & total & 73.4 & 51.8 & 21.6 & 76 & 68 & 8 \\
\hline
\end{tabular}

catalog data (column (3)). In Table 1, the *** sign indicates snowfields ${ }^{1}$ that are not listed in the catalog.

Table 2 presents the integrated data of glaciers (the total area and number) for the corresponding sizes of glaciers in the r. Rioni basin. Data from the catalog is are placed in column (1), and SRS data is in column (2). $\Delta$ - indicates differences in areas and quantities between the catalog and SRS data.

The Aanalysis of Table 2 shows that in the glacial basin of the r. Rioni in the past (catalog data), the total area of glaciers was $73.4 \mathrm{~km}^{2}$. At present, the area of glaciation has decreased by $21.6 \mathrm{~km}^{2}$, and its value makes $70.6 \%$ of the catalog data; in the past, the number of glaciers was

1 Snowfields - motionless natural accumulation of snow, snow cover, snow cover season (seasonal snow cover) or not melting throughout the year (permanent snow cover, overflow). During the degradation of glaciers, snowfields act as their remnants.
76. There were 11 large, 29 medium and 36 small glaciers. Currently, according to SRS data, due to the impact of the current climate change, there exist 8 large, 13 medium and 47 small glaciers, a total of 68 glaciers. Thus, the total number of glaciers decreased by 8 . The number of remaining glaciers amounted to $89.5 \%$ of the one existing in the catalog.

It is important to determine the possible complete melting time of the glaciers in r. Rioni basin. For that, the largest glacier Boko from the basin r. Rioni basin is chosen. It is natural that when this glacier melts completely, it means that all other glaciers will be fully melted. The methodology for determining the retreat rate of the glacier tongue is given in Kordzakhia et al. (2019). To determine the average retreat rate of the Boko glacier and analysis of retreat trends, the dynamics of the glacier retreat was created based on the SRS images for the time range 1977-2015 (Figure 2).

In different years, the location of the glacier tongue is shown by different color contours. The retreat locations 


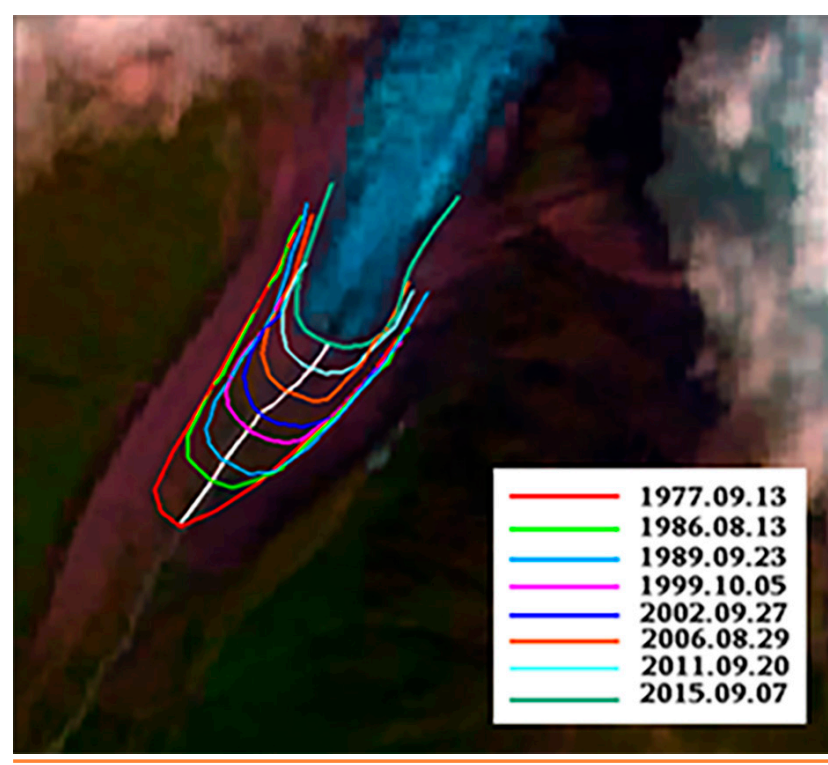

Figure 2 The schematic picture of glacier Boko retreat

and lengths are calculated using the white zigzag line that crosses the contours of the glacier.

Based on Figure 2 the retreat distances were calculated. It was determined that the retreat of the Boko glacier with a high probability can be described by a parabola (Figure 3). For the Boko glacier, the parabola equation is: $y=0.0542 t^{2}+$ 13.717t.

To determine the expected time of the complete melting of the Boko glacier, a climate change scenario so-called business as usual (BaU) was used.

Calculating the period when the length of glacier Boko $(7,856 \mathrm{~m})$ will be decreased and be equal to zero, we achieve that the time for the Boko glacier full melting is 197 years.

It means that the Boko glacier and hence, all the glaciers from r. Rioni basin will disappear in 2,175.

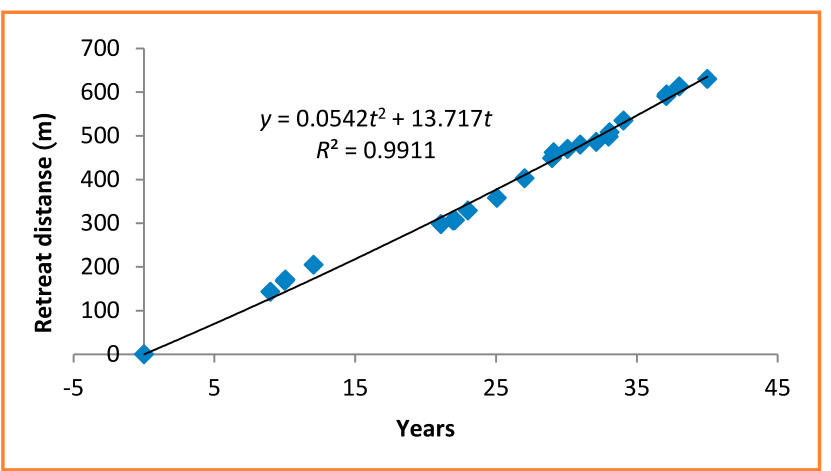

Figure 3 Boko Glacier Retreat

\section{Conclusion}

The impact of the current climate change on the degradation of glaciers of the r. Rioni basin can be summarized as follows:

1. The area of glaciation of the glacial basin of the r. Rioni and the number of glaciers have declined significantly over the past 50 years.

2. The area of glaciation of the $r$. Rioni basin has decreased by $21.6 \mathrm{~km}^{2}$, i.e. to $70.6 \%$ of the original area according the; the number of glaciers has decreased by 8 units, which is $89.5 \%$ of the existing in the catalog.

3. Boko glasier glacier estimated complete melting time is 197 , assuming the BAU scenario of the current climate change.

\section{References}

Abikh, G.V. (1870). Iccledovanie nastoiacshchikh i drevnikh lednikov Kavkaza. Otdel 1. Opisanie nine sushchectvuiuchego Devdorakskogo lednika i sledov deistvia prerhnikh lednikov v doline Tereka. Otdel 2 . O sledakh prerhnikh lednikov $v$ dolinakh rek Assi, Narti-dona i Shasni. G. Abikh; Per. F. Fon-Koshkul. Tiflis (42 p.) (in Russian)

IPCC Special Report on the Ocean and Cryosphere in a Changing Climate (2018).

Khatisyan, G.S. (1864). Kratkii ocherk deistvii dvukh komissii dlia issledovaniia Kazbekskikh lednikov v 1862 i 1863 gg. Tiflis: Zap. KORGO, 6(2), 220-230 (in Russian).

Kordzakhia, G. I., Shengelia, L.D., Tvauri, G. A., Dzadzamia, M. SH. (2016). Impact of modern climate change on glaciers in East Georgia. Bull. Georg. Nat. Acad. Sci., 10(4), 56-63.

Kordzakhia, G. I., Shengelia, L.D., Tvauri, G. A., Dzadzamia, M. SH. (2019). The climate change impact on the glaciers of Georgia. Journal World Science, 1(4(44)), 29-34. DOI: https://doi.org/10.31435/rsglobal_ws.

Maruashvili, L.S., Kurdgelaidze, G.M., Lashkhi, T.A., Inashvili, SH.V. (1975). Katalog Lednikov SSSR (T. 9, vip 1. ch. 2-6). Zakavkazie i Dagestan, L.: Gidrometeoizdat (in Russian).

Panov, V.D., Borovik, E.S. (1977). Katalog Lednikov SSSR (T. 8, ch. 13. 1977). Severni Kavkaz: Gidrometeoizdat (in Russian).

Pellika, P., Gareth Rees, W. (2010). Remote sensing of glaciers: techniques for topographic, spatial and thematic mapping of glaciers (pp. 330).

Tsomaia, V.Sh. (1975). Katalog Lednikov SSSR (T. 9, vip. 3, ch. 1). Zakavkazie i Dagestan, L.: Gidrometeoizdat (in Russian).

Tsomaia, V.Sh., Drobishev, O.A. (1970). Resultati glatsiologicheskikh nabliudenii na lednikakh Kavkaza. Trudy ZakNIGMI, 45(51), 141-146. (in Russian).

Tsomaia, V.Sh., Drobishev, O.A. (1977). Katalog Lednikov SSSR (T. 8, ch. 11). Severni Kavkaz, L.: Gidrometeoizdat (in Russian). 